\title{
EFFECT OF PASSIVE SMOKING ON OTITIS MEDIA IN CHILDREN-AN OBSERVATIONAL STUDY
}

\author{
Dr. S. M. Kanade ${ }^{1}$, Dr. Priyadershini Rangari ${ }^{\star 2}$ \\ ${ }^{1}$ M.B.B.S., M.S.(ENT), Head And Ad-hoc Professor, Department of Otolaryngology, Rajiv Gandhi Medical College and Chhatrapati \\ Shivaji Maharaj Hospital, Thane, Maharashtra, \\ ${ }^{2}$ MDS (Oral Medicine And Radiology), Assistant Professor, Department Of Dentistry, Sri Shankaracharya Medical College, Bhilai, \\ Durg, Chhattisgarh.
}

DOI: https://doi.org/10.15520/ijmhs.v9i6.2604

Accepted 15 Jun 2019; Received 28 May 2019; Publish Online 21 Jun 2019

\begin{abstract}
Background: Otitis media is a common infection in young children. Multiple studies have looked at the impact of environmental tobacco smoke (passive smoking) on children and the incidence of otitis media infections.

Objectives: This study was conducted to evaluate the correlation of environmental and parental smoking on otitis media in children of age range between 0-12 years.

Methods: This was an observational study conducted on clinically diagnosed otitis media in 0-12 year age children. Parents of these children answered a questionnaire that included information about otitis media events and the number of recurrences, environmental tobacco smoke exposure and the source, and if the mother smoked during pregnancy.

Methods - This was an observational study conducted on 320 clinically diagnosed otitis media in 0-12 year age children. The study was performed in five year period from March 2009 to March 2014. All the patients were observed in routine OPD check up by a single observer. A pre designed Performa was used to record relevant information like patient data, history, clinical findings and investigation report from individual cases.

Results: The male predominance was observed. fourth group was of 9-12 year age with most prevalent patients having either form of disease; this was because of more than three years of exposure to passive smoking. The most prevalent disease was observed in under poverty line people. Patients were having parental smoking at home were more prevalent to AOM and CSOM.

Conclusion: The results support a relationship between the exposure of passive smoking and prevalence of recurrent AOM and CSOM in children.
\end{abstract}

Key words: Otitis Media-Parental Smoking-Passive Smoking-Suppuration-Tobacco Smoke.

\section{INTRODUCTION}

Otitis media $(\mathrm{OM})$ is one of the severe healthcare problems in the world because of the suffering it poses upon the patient and the family and also because of the economic burden it forces the health care system. Otitis media is defined as an inflammation of the middle ear, without having any specific aetiology or pathogenesis. Because, all sinuses of the temporal bone are contiguous, infection of the middle ear may also cause inflammation and infection in the other three regions of sinuses. [1] Otitis media is the inflammation

^Email: drpriyakasture@gmail.com. of the mucous membrane of the middle ear which includes the middle ear cavity, mastoid air cells, mastoid antrum and the Eustachian tube. [1, 2] If the inflammation is associated with a discharge from a perforation in the tympanic membrane, suppurative Otitis media results. It can be acute or chronic. [3] It is one of the most common infectious diseases of the childhood in the world. Infections of the middle ear cleft are common in children. More than half of children will have suffered at least one attack by their third birthday. Chronic suppurative otitis media (CSOM) is a middle ear disease entity whose definition is controversial. While the World Health Organization defines CSOM as ear discharge lasting 2 weeks or more through a persistent tympanic mem- 
brane perforation [4], otolaryngologists define the duration of discharge as more than 6 weeks. [5, 6] This condition is estimated to affect between 65 and 330 million people worldwide, $60 \%$ of whom have significant hearing loss. Chronic ear diseases encompass conditions in which there is long standing inflammation in the middle ear. $[7,8]$ The disease entities include CSOM as well as otitis media with effusion, a condition where there is persistent fluid in the middle ear cavity without signs of suppuration. [9]

Considering the recurrent nature of middle ear infections, which may be painless, and the fact that children are most affected yet least able to express themselves, this disease entity tends to be under diagnosed. Delay to diagnosis may result in a higher rate of post infection complications. Therefore, it is recommended to avoid risk factors as a way to prevent the first episode. [8, 9] Risk factors include poor hygiene, malnutrition, overcrowding, frequent upper respiratory tract infections, failure to breastfeed, prolonged use of a pacifier, frequent in a day-care centre, and exposure to passive smoking. [10] Environmental tobacco smoke (ETS) is an important public health problem causing adverse effects on the health outcomes of children. [9, 11] Parental smoking has an increasing impact on infectious and noninfectious lower respiratory tract diseases in children. [12]

Eustachian tube dysfunction is central to the development of middle ear disease of middle ear disease. Secondhand tobacco smoke (SHS) may contribute to Eustachian tube dysfunction, Mucociliary clearance, Adenoidal hyperplasia, Mucosal swelling, Frequency of upper respiratory tract infections. Parental smoking is linked with middle ear disease among children and is likely to be a cause. [13]

There are very few studies have found a correlation between environmental and parental smoke and acute otitis media (AOM) and other adverse otologic outcomes. Given its high personal and societal costs and the divergent findings of the effect of passive smoking on middle ear disease, the aim of the current study was to assess the impact and possible determinant factors of passive smoking on recurrent (two or more) episodes of AOM and CSOM.

\section{MATERIAL AND METHOD}

This was an observational study conducted on clinically diagnosed otitis media in 0-12 year age children visited in the outpatient Department Of Otolaryngology, Rajiv Gandhi Medical College and Chhatrapati Shivaji Maharaj Hospital, Thane, Maharashtra, India. The study was performed in one year period from March 2009 to March 2014. The age range of patients was between 0-12 years. Approval from Institutional ethical committee was taken before initiation of the study.

We defined middle ear infections as an inflamed eardrum or presence of pus in the external auditory canal or a wet or dry tympanic membrane perforation. Thereafter, a semistructured questionnaire was administered to the parent or guardian of the sampled child seeking information on demographics of the child, history of middle ear infections, where they sought treatment, and the nature of treatment received, as well as exposure to risk factors. A pre designed Performa was used to record relevant information like patient data, history, clinical findings and investigation report from individual cases. Parents of these children answered a questionnaire that included information about otitis media events and the number of recurrences, environmental tobacco smoke exposure and the source, and if the mother smoked during pregnancy.

Auroscopy/otoscopy: An otoscope with a good bulb and a good power source, and the tympanic membrane which is not occluded by cerumen, are necessary to make the correct diagnosis of Otitis media. [1, 2] The discharge may be serous, serosanguineous or Mucopurulent. Removing cerumen and crying can cause erythema of the eardrum; therefore solely erythema of the tympanic membrane should not be the basis for the diagnosis of AOM. In OME, Otoscopic findings include air-fluid levels and clear or tawny ear fluid and can be associated with negative ear pressure. In CSOM, visualisation of the tympanic membrane would reveal perforation. If the perforation is wide, the condition of the middle ear mucosa can be assessed easily. Also polyps, crusts, discharge may be seen and identified. $[6,7]$

Pneumatic otoscopy/auroscopy: A pneumatic otoscope has a rubber suction bulb and tube which is used to examine mobility of the tympanic membrane. Pneumatic Otoscopy is helpful in correct diagnosis of AOM from "red ears". If the fluid accumulates in the middle ear, there will be decreased mobility of the tympanic membrane and bulging of the TM can be seen. $[5,8]$

All the patients were observed in routine OPD check up by a single observer. Detailed clinical examination was performed including a general systemic examination and thorough examination of the ear using otoscope. The character of the tympanic membrane was observed in detail. The three standard tuning fork tests (Weber's, Rinne's and Absolute Bone Conduction tests) were done. All candidates underwent a pure tone audiometry and all cases with an intact tympanic membrane underwent immitance studies. Pure tone audiograms were assessed for type and percentage of hearing loss. ENT examination was done by tuning forks - (Gardiner Brown Tuning Forks of $256 \mathrm{~Hz}, 512 \mathrm{~Hz}$, and $1024 \mathrm{~Hz}$ ) and otoscopy done by a Heine Quality pocket otoscope.

All the data was collected and transferred to Microsoft office word excel 2010. Statistical analysis was performed by using MS Excel-2010 and SPSS software trial version 21.0.

\section{RESULT}

This was an observational retrospective study performed on 320 children with the age range between $0-12$ years. All the subjects were of pre diagnosed middle ear infection. The study period was of five years. Following data was collected and summarized in two tables.

Table 1 explains about demographic variables of the study. The male predominance was observed to be 172 


\section{EFFECT OF PASSIVE SMOKING ON OTITIS MEDIA IN CHILDREN-AN OBSER VATIONAL STUDY

Table 1. demographic variables.

\begin{tabular}{llll}
\hline Demographic variables & Group & Number of patients & $\%$ \\
Gender & Male & 172 & 53.75 \\
& Female & 148 & 46.25 \\
\multirow{4}{*}{ Age group (years) } & $0-3$ & 51 & 15.93 \\
& $3-6$ & 69 & 21.56 \\
\multirow{5}{*}{ Social status } & $6-9$ & 92 & 28.75 \\
& $9-12$ & 108 & 33.75 \\
\multirow{2}{*}{ Period of exposure to smoke (years) } & Under poverty line & 146 & 45.62 \\
& Low economy & 113 & 35.31 \\
& Middle class & 81 & 25.31 \\
Source of passive smoke & $1-2$ & 62 & 19.37 \\
& $>3$ & 38 & 11.87 \\
& Coal/kerosene stove & 22 & 6.87 \\
& Parental smoking & 42 & 9.37 \\
& Industrial smoke & 22 & 13.12 \\
\hline
\end{tabular}

(53.75\%) and female were 148 (46.25\%). Four age group of three year were considered in the study. The age range was 0-12 years. First group was of 0-3 year age which had least prevalent i.e. with $51(15.93 \%)$ patients. Second group was of 3-6 year age with $69(21.56 \%)$ patient; third group was of 6-9 year age with $92(28.75 \%)$ patients and lastly fourth was of 9-12 year age with most prevalent $108(33.75 \%)$ patients having either form of disease.

Patients were divided into three socioeconomic categories i. e under poverty line people who were mostly living in slums with very little or single room or huts, low economy mostly labour and farmers having small houses with joint family and last middle class who have 1-2 floored house. The most prevalent disease was observed in under poverty line people i.e. $146(45.62 \%)$ patient.

Table 1 also gives details about period of exposure to passive smoke. 62 patients exposed to smoke for 1-2 years of time, 38 patients were exposed for 2-3 years of smoke and 22 patients were exposed to passive smoke for more than 3 years. $30(9.37 \%)$ patients had coal or kerosene stove at home, $42(13.12 \%)$ patients were having parental smoking at home, $22(6.87 \%)$ patients were in connection with industrial smoke.

Table 2 describes about the sign and symptoms of acute otitis media (AOM) and chronic suppurative otitis media (CSOM). In Acute otitis media (AOM) 76 (38\%) patients were having fever, $72(36 \%)$ patients had redness, $78(39 \%)$ patients had bulging, $130(65 \%)$ patients had irritability, $38(19 \%)$ patients were having upper respiratory tract infection and $71(35.5 \%)$ patients had discharge from ear. In chronic suppurative otitis media (CSOM) $(n=120)$; discharge observed in $81(67.5 \%)$ patients, $48(40 \%)$ patients had cholesteatoma and $72(60 \%)$ patients had otorrhea. This study showed irritability was the prominent symptom in acute otitis media and least common was URTI. In CSOM, discharge from middle ear was most prevalent symptom.

\section{DISCUSSION}

In this study in Thane district, Maharashtra; we have found that among children visiting an outpatient ENT depart- ment, passive smoking by coal or kerosene stove, parental smoking and industrial smoke doubled the risk of recurrent $\mathrm{AOM}$ and CSOM infections. The male predominance was observed to be $172(53.75 \%)$ and female were 148 (46.25\%). Fourth group was of 9-12 year age with most prevalent 108 $(33.75 \%)$ patients having either form of disease; this was because of more than three years of exposure to passive smoking.

It is not surprising that passive smoking by coal or kerosene stove, parental smoking and industrial smoke predicted recurrent episodes of AOM and CSOM. Alpert et al. [3] have documented that household smoking policies are associated with increased office visits for AOM at the population level.

The role of day care attendance has been documented in the development of AOM and CSOM. [7] Our findings extended the risk factor to children who suffered by passive smoke. On the other hand, mother's part time or full time employment did predict recurrent AOM infections.

This study also uncovered a high prevalence of children exposed to. Table 1 also gives details about period of exposure to passive smoke. 62 patients exposed to smoke for 1-2 years of time, 38 patients were exposed for 2-3 years of smoke and 22 patients were exposed to passive smoke for more than 3 years. $30(9.37 \%)$ patients had coal or kerosene stove at home, $42(13.12 \%)$ patients were having parental smoking at home, $22(6.87 \%)$ patients were in connection with industrial smoke. While some evidence suggests under reporting of childhood exposure to parental tobacco smoke. [11, 12] Other data suggest a moderate correlation, allowing researchers to generally trust what parents say about the second hand smoke exposure of their child. In addition, parents who smoked were more likely to believe that their smoking harmed their child if the mother smoked during pregnancy. These findings show that smoking parents at least acknowledged some harm to their child from their smoking, making their self-reported smoking appear more reliable, even if their reported place of smoking may be less reliable. Our findings on passive smoke exposure $92(29.375 \%)$ are somewhat lower than those of Boldo et al. [14] Using a variety of databases, these investigators 
Table 2. sign and symptoms of disease.

\begin{tabular}{|c|c|c|c|}
\hline \multirow[t]{4}{*}{ Type } & Symptoms & & $\%$ \\
\hline & Fever & 76 & 38 \\
\hline & Redness & 72 & 36 \\
\hline & Fullness & 78 & 39 \\
\hline \multirow[t]{5}{*}{ Acute otitis media $(\mathrm{AOM})(\mathrm{n}=200)$} & Buldging & 100 & 50 \\
\hline & Irritability & 130 & 65 \\
\hline & Upper respiratory tract infection (URTI) & 38 & 19 \\
\hline & Discharge & 71 & 35.5 \\
\hline & Discharge & 81 & 67.5 \\
\hline \multirow[t]{2}{*}{ Chronic suppurative otitis media (CSOM) $(n=120)$} & Cholesteatoma & 48 & 40 \\
\hline & Otorrhea & 72 & 60 \\
\hline
\end{tabular}

estimated ETS exposure among Hungarian children (0-14 years of age) ranging from 41 to $58 \%$ during the period 2002 - 2005. By comparison, Bulgaria had the highest estimated ETS rates (44-76\%) while Sweden had the lowest (19-30\%). Germany's rates were comparable to Hungary's (37-57\%), as were Poland's (38-59\%), Slovakia's (41-55\%) and Croatia's (34-59\%). [15, 16] The current study's findings are also somewhat less than those from the Central European Study on Air Pollution and Respiratory health (CESAR). [14, 17] in which Hungary had an estimated ETS exposure rate among children of $59 \%$. Previous studied denoted the mean age of children was 6.5 years although it should be noted that the mean age of the children in this study was approximately 6 years old.

In Acute otitis media (AOM) $76(38 \%)$ patients were having fever, $72(36 \%)$ patients had redness, 78 (39\%) patients had bulging, 130 (65\%) patients had irritability, 38 (19\%) patients were having upper respiratory tract infection and $71(35.5 \%)$ patients had discharge from ear. In chronic suppurative otitis media (CSOM) $(\mathrm{n}=120)$; discharge observed in $81(67.5 \%)$ patients, $48(40 \%)$ patients had cholesteatoma and $72(60 \%)$ patients had otorrhea. This study showed irritability was the prominent symptom in acute otitis media and least common was URTI. In CSOM, discharge from middle ear was most prevalent symptom. These findings were in accordance with the findings of previous studies conducted by Fabry DA et al [11] and Timmerman AA et al. [15]

This study is subject to a number of limitations. The first limitation deals with generalized ability. A very less number of children were observed to make any definite conclusion. The data may be irrelevant for false history regarding frequency of bidi or cigarette smoking by parents or relative or neighbor. This may be due to tendency of people to hide the reality of smoking habits.

Three cross sectional studies of school- children have related a history of "otitis" or "ear infection" to parental smoking. In two Israeli studies the odds ratios for ear infection among children whose parents smoked were 1.30 (1.04 to 1.64$)$ and 1.12 (1.01 to 1.25$)$. [18, 19]

Moreover, the prevalence of passive smoking exposure among those children and of smoking during pregnancy generally matched those found in other studies carried out in Hungary. [14, 15] Another limitation is the study's reliance on self-report. Parents might be reluctant to reliably report a child's exposure to passive smoking, particularly in the setting of an ENT clinic where cigarette smoking is more likely to be perceived as harmful to the child. On the other hand, parents who smoked were willing to admit that their smoking harmed their child increasing our confidence in the self-reported data. The diagnosis of AOM itself was also based on parental or caregiver report; however, report of AOM by parents has been found to be valid by other investigators. Additionally, this study did not determine the exact living situation of the children evaluated. Recent evidence suggests that even children without known passive and environmental smoke exposure can still show biochemical evidence if they live in multi-unit housing flats. Such misclassification would again bias towards the null and strengthen these findings. Further, we did not ask about smoking of the child, which might be relevant, for example, among adolescents. Finally, biochemical validation of the children's exposure to passive smoke, such as urinary levels, would have greatly strengthened our findings. [20]

In 2001, Hovella reviewed clinical, legislative, media and other efforts undertaken by Hungary to address this problem. [21] He suggested for further research into cultural tailoring needed to be effective. Given the many adverse health effects of second hand smoke, concern regarding childhood environmental and passive smoke exposure has also been global. [19] In 1999, the World Health Organization convened an International Consultation on Environmental Tobacco Smoke and Child Health, declaring that "that ETS is a real and substantial threat to child health, causing a wide variety of adverse health effects in children, including middle ear disease" among many other conditions. [10] Boldo and colleagues, [19] who reviewed European studies on the adverse health effects of ETS among children, including results from eastern and western Europe, confirmed adverse prenatal and post natal health effects in these populations and recognized that such exposure "needs to be reduced urgently". [20, 21] In this context, Dell'Orco et al. argue that childhood ETS exposure is "a specific community responsibility" for all of Europe. [21] In concert with the results of these and other analyses, this study highlights this global need. 


\section{EFFECT OF PASSIVE SMOKING ON OTITIS MEDIA IN CHILDREN-AN OBSER VATIONAL STUDY

5

The male predominance was observed. Fourth group was of 9-12 year age with most prevalent patients having either form of disease; this was because of more than three years of exposure to passive smoking. The most prevalent disease was observed in under poverty line people. Patients were having parental smoking at home were more prevalent to AOM and CSOM. The result supported a relationship between the exposure of passive smoking and prevalence of recurrent $\mathrm{AOM}$ and CSOM. To prevent passive exposure of children to ETS and to support parents and caregivers to quit smoking are a public health priority.

\section{REFERENCES}

[1] Kenna MA. Otitis media with effusion. York: J.B. Lippincott Company; 1998. p. 1297-310.

[2] the burden of Otitis media. Klein JO. 2000;

[3] DW RBT. Epidemiology of Otitis media during the first seven years of life in children in greater Boston: a prospective, cohort study. J Infect Dis. 1989;160:83-94.

[4] Otitis media and its consequences: beyond the earache. Lancet Infect Dis. 2010;10:195-203.

[5] Casselbrant ML, Mandel EM. Hamilton, (ON: BC Decker; 2003.

[6] Otitis media in developing countries. Paediatrics. 1995; $96: 126-131$.

[7] Chronic suppurative Otitis media -Burden of Illness and Management Options. Acuin J. 2004; .

[8] TS KBE, R K. Prevalence of hearing loss in older adults in Beaver Dam, Wisconsin. The Epidemiology of Hearing Loss Study Am J Epidemiol. 1998;148:879-886.

[9] Screening and management of adult hearing loss in primary care: scientific review. Yueh B, Shapiro N, MacLean CH, Shekelle PG. 2003;289:1976-1985.

[10] GBD Study Operations Manual -Final Draft; 2009.

[11] Fabry DA. Davila EP, Arheart KL, Serdar B, Dietz NA, Bandiera FC, Lee DJ. Second hand smoke exposure and the risk of hearing loss. Tob Control; 2011.

[12] International Agency for Research on Cancer. IARC Handbooks of Cancer Prevention, Tobacco Control, Vol 13 Evaluating the effectiveness of smoke-free policies. IARC; 2009.

[13] Maróti-Nagy A, Nagymajtényi L, Rogers T, Easterling D. Support for populationlevel tobacco control policies in Hungary. Paulik;E,. in press.

[14] Öberg M, Jaakkola MS, Woodward A, et al. Worldwide burden of disease from exposure to second-hand smoke: a retrospective analysis of data from 192 countries. Lancet; 2011. $377: 139-146$

[15] Hovella MF, Zakariana JM, Wahlgrena DR, Mattb GE, Emmons KM. Reported measures of environmental tobacco smoke exsposure: trials and tribulations. Tob Control;2000. 9(Suppl III):iii22-iii28.

[16] Gurzau E, Fabianova E, Fletcher T, Brunekreef B. Respiratory symptoms, bronchitis and asthma in children of. Central and Eastern Europe Eur Respir J;20:890-8.

[17] J PGM. Day care and the incidence of otitis media in young children. Otolaryngol Head Neck Surg; 1995.

[18] Timmerman AA, Meesters CM, Anteunis LJ, Chenault MN, Haggard MP. Psychometric evaluation of the OM8-30 questionnaire in Dutch children with otitis media. Eur Arch Otorhinolaryngol; 2008.
[19] D BJP. Parental smoking and childhood cancer: results from theUnited Kingdom Childhood Cancer Study. Br J Cancer;88:373.

[20] Medina S, Oberg M. Health Impact Assessment of Environmental Tobacco smoke in European children: sudden infant death syndrome and asthma episodes. Boldo. 2010;125:47887.

[21] Moshammer H, Hoek G, Luttmann-Gibson H. Parental Smoking and Lung Function in Children An International Study. American Journal of Respiratory and Critical Care Medicine. 2006;173:1255-63.

\section{AUTHOR BIOGRAPHY}

Dr. S. M. Kanade M.B.B.S., M.S.(ENT), Head And Adhoc Professor, Department of Otolaryngology, Rajiv Gandhi Medical College and Chhatrapati Shivaji Maharaj Hospital, Thane, Maharashtra,

Dr. Priyadershini Rangari MDS (Oral Medicine And Radiology), Assistant Professor, Department Of Dentistry, Sri Shankaracharya Medical College, Bhilai, Durg, Chhattisgarh. 